\title{
How policy can make a world of difference for small and medium-sized enterprises
}

Written by: OECD

Last update: 23 January 2020

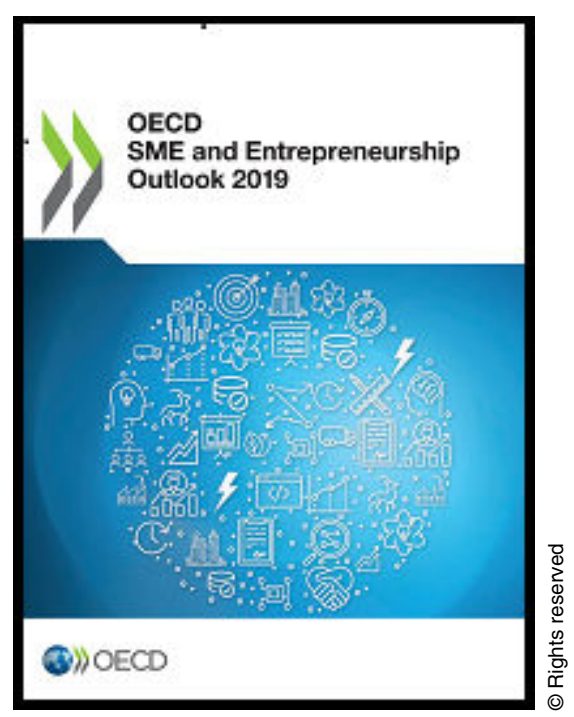

How policy can make a world of difference for small and mediumsized enterprises - book cover I How policy can make a world of difference for small and medium-sized enterprises - book cover of SME and Entrepreneurship outlook 2019

Did you know that nearly all businesses in OECD countries are in fact small and medium-sized enterprises? Not only do these SMEs represent $99 \%$ of the number of firms, but they also generate about $60 \%$ of employment and between $50 \%$ and $60 \%$ of value added. No wonder policymakers should view SMEs as key for sustainable and inclusive economic growth.

SMEs are instrumental to ensure that our economies and societies adapt to major transformations, such as globalisation, digitalisation, environmental pressures and demographic changes. 
Governments tend to share common broad orientations for SMEs and entrepreneurship. On the other hand, national visions and approaches to SME policy design and implementation differ, with diverging viewpoints in some areas on how to unleash SME potential. While some countries have sought to mainstream SME policy considerations in other policy agendas, others specifically target SMEs with tailor-made instruments, often combined with place-based or sector-wide policy mixes.

Regardless of the strategic approach, there is a broad-based focus on: accelerating innovation diffusion to SMEs and ensuring they keep pace with the digital transformation; engaging SMEs in upskilling; and scaling up innovation networks and linkages with multinationals.

Policy efforts also tend to aim to level the playing field by encouraging more competition, for instance, or opening up public procurement to smaller contract lots, simplified procedures and training, and through innovative procurement or targeted support for SME innovation uptake.

OECD governments have also undertaken reforms aiming to lower administrative and tax burdens on firms, but the pace of structural reforms has slowed in recent years, particularly in regard to insolvency regimes and offering entrepreneurs a second chance.

There are challenges on the horizon. The SME engine has restarted, driving job creation since 2010, but new jobs have often been in low-productive low-paid activities. Between 2010 and 2016, close to $90 \%$ of the net new jobs in France, 75\% in the United States, and $66 \%$ in Germany and the United Kingdom, were in lowwage sectors, which contributed to a stagnation in average wages and to widening inequalities.

Some SMEs are taking the lead at the knowledge frontier: there are major innovation and productivity champions, particularly in specialised services such as professional, scientific and technical activities, where size does not play such a key role. Yet, many SMEs are stalling when it comes to investing in the skills, tech and innovation that would be needed to boost wages and productivity.

In particular, SMEs lag in digitalisation. Policies are needed to make them more proactive in adopting digital practices and in protecting their data, and to be better prepared to face cybersecurity threats. More effort is needed to improve skills to manage their digital transformation and engage more employees in training for digital workplaces. Recent progress in engaging in vocational education programmes and in closing the training gap with large firms must be strengthened in order to bridge the skills divide.

Policies should help SMEs take advantage of new opportunities in the production revolution by embracing the likes of big data analytics and artificial intelligence to improve the differentiation and customisation of their goods and services.

2 www.oecdobserver.org I How policy can make a world of difference for small and medium-sized enterprises 
Digitalisation can help SMEs integrate into global markets and value chains. Internationalisation represents another important channel to increase SME productivity and wages. In fact, data show that wage gaps with large firms, which typically pay employees $20 \%$ more than small businesses, are smaller for exporting SMEs.

How policy can make a world of difference for small and medium-sized enterprises - chart

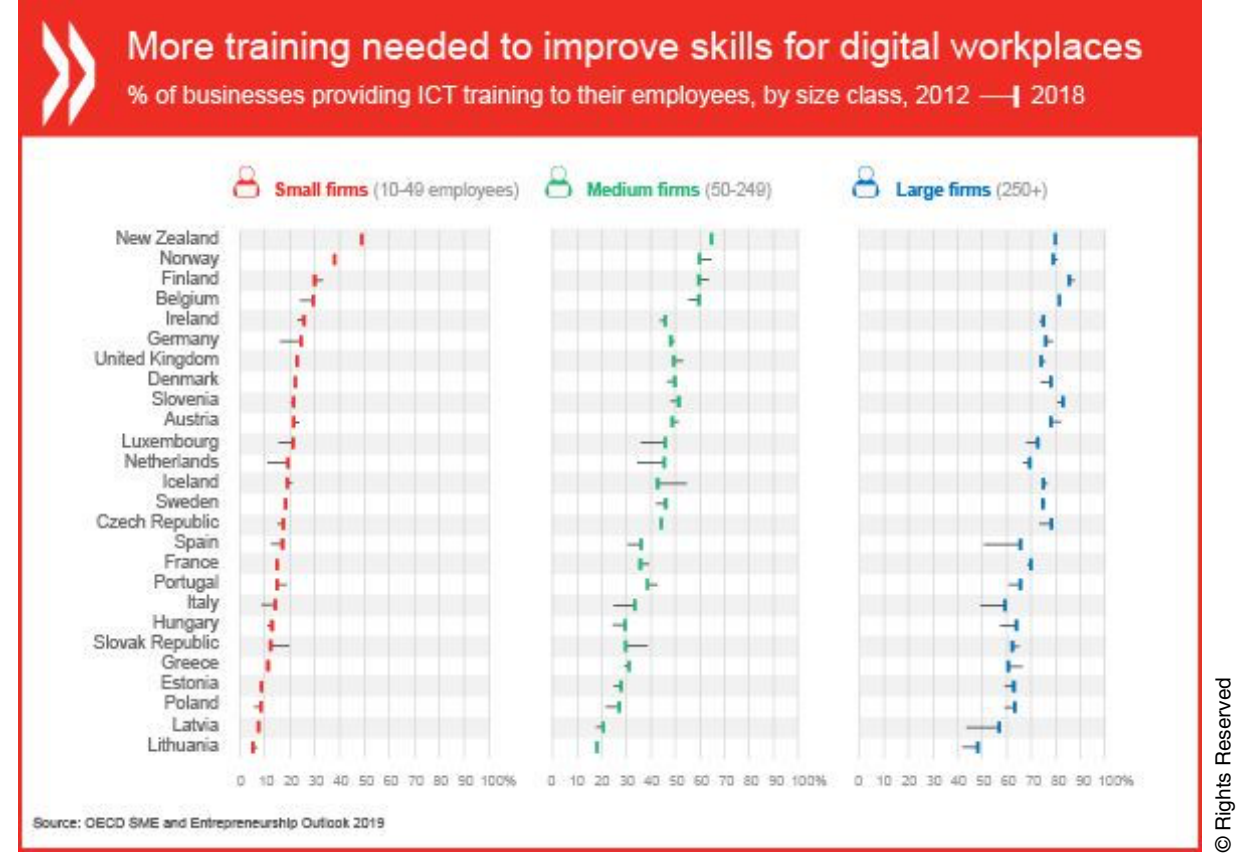

Chart for How policy can make a world of difference for SMEs - chart title: More training needed to improve skills for digital workplaces.

OECD SME and Entrepreneurship Outlook 2019

Action is needed now, to enable SMEs to make the most of emerging opportunities but also to ensure they are better prepared in the event of a new economic slowdown. In fact, as trade tensions increase and market conditions for SMEs tighten, the room for them to benefit from digitalisation and globalisation may narrow.

Public action has to take the wide diversity of SMEs into account to be effective. It should also address the broad range of factors that can affect their business environment and which cross over multiple policy domains, from regulation to infrastructure, competition and tax, not to mention national and subnational levels of policy governance.

Many of these issues are addressed in the SME and Entrepreneurship Outlook. SMEs can help us reach new heights, and with international co-operation and more evidence on good practices, policymakers can help SMEs and entrepreneurs play a fuller part in building more resilient, sustainable and inclusive societies.

@OOECD Observer June 2019

3 www.oecdobserver.org I How policy can make a world of difference for small and medium-sized enterprises 


\section{References}

OECD (2019), OECD SME and Entrepreneurship Outlook 2019, OECD Publishing, Paris, https://doi.org/10.1787/34907e9c-en http://dx.doi.org/ 